See discussions, stats, and author profiles for this publication at: https://www.researchgate.net/publication/283016248

\title{
Written Communication Intercultural Model: The Social and Cognitive Model
}

Article in The International Journal of Interdisciplinary Social Sciences: Annual Review · January 2011

CITATION

1

2 authors:

Rosario . Arroyo

University of Granada

59 PUBLICATIONS 137 CITATIONS

SEE PROFILE
READS

286

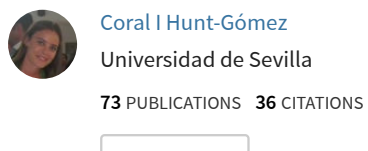

SEE PROFILE

Some of the authors of this publication are also working on these related projects:

Escritura científica, multilingüismo y PLE en la Universidad View project

Transcreación web para la difusión de información corporativa de las pymes españolas del sector sanitario View project 


\title{
Written Communication Intercultural Model: The Social and Cognitive Model
}

\author{
Rosario Arroyo (Granada University, Spain) \\ Coral Ivy Hunt Gómez (Granada University, Spain)
}

\section{Introduction}

The purpose of this article is to introduce a writing development model that integrates cognitive, affective-emotional and socio-cultural models of writing. It is a global model which tries to orientate writing didactics designs, especially in the multicultural and technologic contexts of the Western societies of the $21^{\text {st }}$ Century. In this sense, the main contribution of this article to the Interculturality and the Writing Development areas of knowledge is to offer a Metasociocognitive Model for Written Comprehension. This Model is based in reflection and empiric research carried out during the latest decades. The Metasociocognitive model is a design agreed by the consensus of researchers in the Writing Areas which opens new ways for the teaching of Written Composition integrated in the cultural and linguistic diversity of Western Societies.

In order to explain the Sociometacognitive Model we start from the Writing metacognition processes. Metacognition is a mental process which establishes links among psychomotor, cognitive, affective and social processes. All these links determine the development of Written Composition and vice versa.

Although all cognitive models on written composition include metacognition, only the most recent reviews of the literature (Hayes, 1996; Bruning \& Horn, 2000; Salvador, 2005) include metacognitive components of an affective and emotional nature. The inclusion enhances the cognitivist perspective on the development of written composition. Metacognition includes the wide knowledge that individuals have about a range of factors: a) other individuals as thinking subjects; b) cognitive tasks or goals; c) strategies used to achieve these goals; d) the way in which these factors interact; e) contents or objects on which individuals' cognition relies. Metacognition is the area of knowledge that is concerned with the "cognition of cognition" (Flavell, 
1985, 45) and it implies three types of knowledge: procedural, declarative and conditional (Brouwn, 1985). Specifically, in written composition, metacognition is seen as a self-regulating, self-controlling and creative process of all knowledge, processes and variables involved in the composition of a text.

Thus, the metacognition of written composition is a process that implies, in the writer, firstly: a) knowing what a text is; b) knowing why a text is written; c) knowing what the purpose of that text is; d) knowing what composing a text is; e) knowing how to compose a text; and f) performing it according to the goals that are set (selfregulation). Secondly, metacognition includes those affective and social variables that are favourable to it; that is, in a self-controlled way.

\section{METACOGNITION IN WRITTEN COMPOSITION}

All these dimensions of metacognition in written composition are shown in Figure 1. 


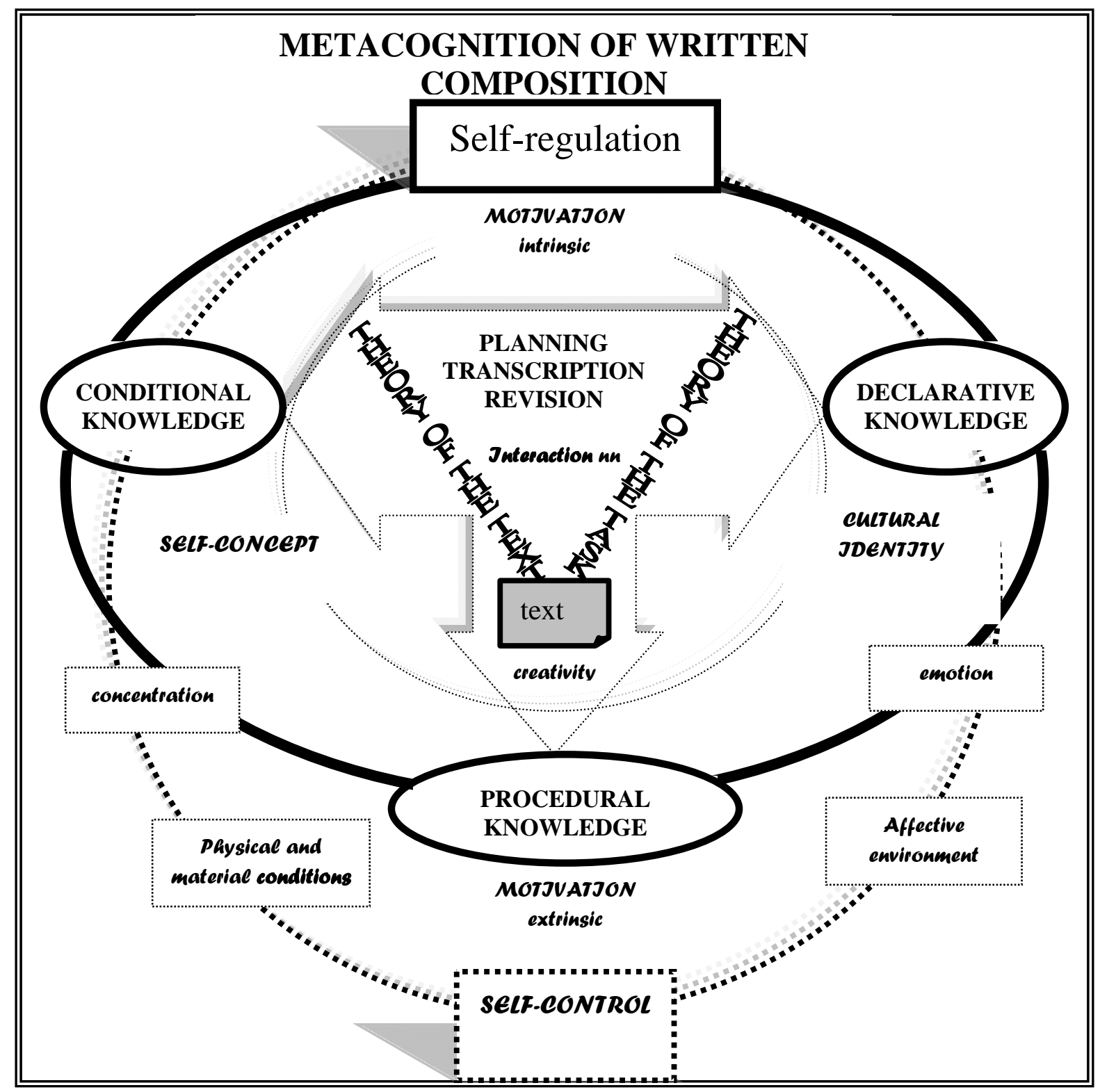

Figure 1. Metacognition in written composition

Metacognition in written composition implies the following:

- being conscious of the personal intentions or purposes that lead to the writing of a text (duty, fun, the need of expressing ideas, denouncing something, applying for something, sharing experiences and/or feelings (see Beard, 2000, 2005 for discussions of the implications for educators) and its social functions (waking the others' conscience up, informing others about something that happened, promoting values in others, and engendering feelings in others);

- Being able to self-regulate one's own cognitive and motor performance in written composition, according to the knowledge acquired on what a text is what composing a text is and the way in which a text is composed. In order to achieve 
this, an individual must be able to choose and apply strategies according to the intentions or purposes established;

- being able to self-control one's own emotional state in the process of written composition and, in this way, generating both the necessary concentration in order to perform the tasks of written composition and the appropriate feeling for the text that is being written;

- reaching an intrinsic motivation for written composition, by means of building a defined cultural identity, based on an optimum self-concept that allows the individual to activate all knowledge and strategies needed for the composition of the text;

- Providing the extrinsic motivation for written composition, creating the most suitable physical conditions (spaces, times, resources) for the composition of that text and searching for the appropriate social interactions in order to enrich the text in a creative way, in its form, contents, structure and purpose.

Each dimension is described in the following sections.

\subsection{Basic Metacognitive Competences in Written Composition}

As highlighted in Figure 1, the purely metacognitive operations in written composition are: procedural knowledge, declarative knowledge, and conditional knowledge about the composition of a text. These three categories of knowledge, which are recursive, form a unit of connected knowledge. This means that all this knowledge is never considered in a pure and isolated way. Thus, declarative knowledge about the planning, transcription and revision of written composition is not possible without previously building a conditional knowledge, that is to say: a) a "theory of the text" (metatextual knowledge about the structure and contents to write about). In the same way, declarative knowledge involves being conscious of the procedures of written composition and thus improving and enlarging them. On the other hand, conditional knowledge is validated in the procedural knowledge and is expressed in the declarative knowledge.

The following sections will put forward in further detail what these different types of knowledge comprise. 


\subsubsection{Procedural Knowledge of Written Composition}

Procedural knowledge (knowing how to compose a text), also known as procedural memory, is characterised by being a non-declarative kind of knowledge. It is a knowledge mainly self-regulated in an automatic way, that is to say, unconsciously. This type of knowledge includes: a) the knowledge of the motor abilities needed in order to compose a text; and b) the knowledge of the cognitive abilities needed in order to compose a text. This is a knowledge that is acquired by means of a simple conditioning, a simple associative learning, a perceptive representation, in a visual, aural and kinaesthetic way, by means of imitation or 'habituation', a justified repetition of an act or activity.

Procedural knowledge assumes the knowledge of how to perform a motor and mental activity without the need of explaining that activity (how and why it is done). Writing, motor and mental activities of a procedural nature are those associated with the processes of planning, transcription and revision.

These processes are performed in a given moment with a given aim. It is possible that the subject may not be able to bring to his/her own conscience the operations and strategies implied in the process. This knowledge is stored as automatic procedures which allow writing (in different levels of competence), although there will always be a certain degree of metacognitive reflection, in spontaneous self-correction or in related initiatives such as asking others for help in order to perform writings successfully.

\subsubsection{Declarative Knowledge of Written Composition}

Declarative knowledge is conscious and verbalisable (the knowledge of what must be done in order to compose a text) and is also known as declarative memory. It is characterised by the possibility of observing the final product in an introspective and conscious way. This knowledge is activated by:

- Operative or working memory;

- Semantic memory or factual experiential knowledge;

- Episodic or autobiographic memory 
Declarative knowledge is a means of making an action performed explicit, in global terms: knowing how to explain what is done when composing a text. In the composition of a text, this knowledge includes what each one of the processes involved consists of and of the necessary operations in order to perform these processes in the following ways.

\section{A. Declarative Knowledge of planning}

Declarative planning consists of thinking why and for which audience one is going to write and organise ideas, applying the following operations:

\begin{tabular}{|l|l||}
\hline \hline Planning operations & Consists of: \\
\hline Audience & $\begin{array}{l}\text { Defining the characteristics of who will read the text and the way in } \\
\text { which this consideration will shape the form, structure and contents } \\
\text { of the text }\end{array}$ \\
\hline Raise objectives & $\begin{array}{l}\text { Determining the intentions and purposes of the text and how these } \\
\text { will condition the form, structure and contents }\end{array}$ \\
\hline Generation of ideas & $\begin{array}{l}\text { Producing the ideas needed for the building of the text, referring } \\
\text { both to contents and procedure }\end{array}$ \\
\hline Selection and sequence of ideas & Selectively work on the ideas generated, applying different criteria \\
\hline Classify ideas & $\begin{array}{l}\text { Putting the ideas to be written in order, according to the structure of } \\
\text { the text }\end{array}$ \\
\hline Regrce of ideas & $\begin{array}{l}\text { Using resources and strategies for the search of ideas } \\
\text { memorise what is already planned, with the purpose of using it } \\
\text { afterwards as a guide for the transcription of the text }\end{array}$ \\
\hline
\end{tabular}

\section{B. Declarative knowledge of transcription}

Declarative transcription consists of developing the structure and form of the text. Thus, transcribing means the application of the following operations:

\begin{tabular}{||l|l||}
\hline Transcription operations & Consists of: \\
\hline Syntactic order & $\begin{array}{l}\text { Building sentences that make sense and connected with each other } \\
\text { (applying morpho-syntactic abilities) to adapt the text to the idea }\end{array}$ \\
\hline Textual coherence & $\begin{array}{l}\text { Using linkers and expressions/idioms in order to join the ideas that } \\
\text { are communicated }\end{array}$ \\
\hline Richness of vocabulary & $\begin{array}{l}\text { Using a great variety and quantity of written words in order to } \\
\text { express ideas (by applying orthographic skills) }\end{array}$ \\
\hline Choice of vocabulary & Choosing words according to the type of text, style and contents \\
\hline Graphic production & Calligraphic and graphic representation skills of punctuation signs \\
\hline
\end{tabular}




\section{Declarative Knowledge of Revision}

Declarative revision consists of the process by which the subject evaluates the written discourse in the light of previous planning, in order to change whatever is necessary. The subject must perform the following operations in revision:

\begin{tabular}{||l|l||}
\hline Revision operations & Consists of: \\
\hline $\begin{array}{l}\text { Adaptation of the form and/or the } \\
\text { contents to the planning }\end{array}$ & $\begin{array}{l}\text { Detecting and changing those words, sentences and paragraphs } \\
\text { that do not adapt to the structure and ideas of the text to be written }\end{array}$ \\
\hline $\begin{array}{l}\text { Structure and vocabulary of the } \\
\text { sentence }\end{array}$ & $\begin{array}{l}\text { Detecting and changing the words, sentences and paragraphs... } \\
\text { that do not make sense }\end{array}$ \\
\hline Punctuation and spelling & $\begin{array}{l}\text { Detecting and changing spelling mistakes of words and } \\
\text { punctuation mistakes in sentences }\end{array}$ \\
\hline Calligraphy & Detecting and changing the calligraphy of words \\
\hline Revision by others & $\begin{array}{l}\text { Assessment of the text by other persons who have not written it } \\
\text { and who suggest changes }\end{array}$ \\
\hline Revision by the writer & Evaluating and changing his/her own text \\
\hline
\end{tabular}

\subsubsection{Conditional Knowledge of Written Composition}

Conditional knowledge (what to do in order to reach an objective) is a strategic knowledge (how to apply a process, operation or skill) and is dependent upon the ultimate purpose (knowing why and for whom a text is composed) involved in the task to be fulfilled. This knowledge involves knowing when and why to apply each strategy to achieve the objectives that have been established. For instance, if the personal intentions (purposes) of the author of the text are to achieve a good mark in the subject of language, special attention in the revision of the text will be given to the operations of correction of spelling and punctuation. In order to do so, different strategies can be used, such as: a) applying the word processor's spelling correction tool to the text; b) looking up in the dictionary the words with a difficult calligraphy or punctuation; c) looking up spelling and punctuation rules; d) writing the word in different ways and retaining the form which seems intuitively more likely. Some of these strategies can be used before or after writing the words, according to the writer's own decisions.

Conditional knowledge requires a "theory of the task" and a "theory of the text" (Peronard, Velásquez, Crespo \& Viramonte, 2002, 134):

- having a "theory of the task" means having a clear and different idea of the possible aims (purposes and/or functions) of the text that is going to be written and of how these aims influence: a) the form of the text (format, length, font, 
margins, pictures, graphics); b) the contents of the text (information, message); and c) its structure (argumentative, narrative, expository). The "task" is understood in terms of the goal pursued and the cognitive effort made. The task includes taking into account the people or audience who will read the text and the possible strategies that can be applied in order to achieve the goal. Thus, totally different tasks are writing a text for a class assignment, for its publication in the press or for a personal diary

- Conditional knowledge also requires a knowledge about the characteristics of the text that is going to be written, that is to say, a "theory of the text" or "metatextual” knowledge, as a part of the writing task. This means:

o Knowledge about the superstructure of the text, whether it is narrative, argument, expository, poetic, epistolary.... Knowing the superstructure of the text to be written allows for the introduction of the different elements of content, in an ordered way, giving sense to the whole of the text.

o Knowledge of the coherence of texts and their hierarchical semantic structure, that is, the knowledge that in a text some clauses are more important than others and others are secondary, complementary or exemplifications. Knowing this hierarchic nature of texts helps writers to retain, in their working memory, those more important clauses in order to give a macrostructure to their texts (creating unity, coherence, and the linking of ideas)

o Linguistic knowledge of a semiotic nature, that is to say, knowing the intentional meanings of language in relation to the extra-linguistic world. Thus, according to the "theory of the task" each individual has (knowledge about "why" to write, for "whom" we write, "where and with what" to write), the writer will focus on the context he/she wants to express and on the system of verbal symbols he/she has in order to express it. This system of symbols is acquired in the processes of social interaction, and means much more than just transcribing graphic signs. These processes are one of the bases of the development of written composition from the socio-cultural perspective. 
The previous arguments highlight the recursive character of the processes of written composition. The different types of declarative and procedural knowledge, as well as those which make up the "theory of the task" and the "theory of the text" (conditionals), are those types of knowledge that are concerned with the operations of planning, transcription and revision which do not operate in a linear way. This recursiveness is clearly noticeable in the update of conditional knowledge that is a procedural and declarative knowledge of every writing processes and operation, but performed in a self-regulated way.

- Self-regulation has a key role in the development of written composition, as it means the adjustment of performance to the demands of the task (Graham \& Harris, 1999), demands that may be physical, as well as personal and/or social. In short, when the processes and operations in written composition are performed in a conscious, verbalizable and self-regulated way, we can say that the writer fully applies the metacognitive operations, that is, he/she updates the metacognitive process.

- In the metacognitive model being discussed, we discover an interaction between the cognitive processes (planning, transcription, revision) and between these and the text in the development of conditional knowledge; to be precise, a theory of the task and a theory of the text. This is so because conditional knowledge implies becoming aware of all competences (linguistic, of content, writing strategies, purpose, audience) in the composition of a text, in order to select them in an organised way (planning) and perform them (transcription and revision of the text) in a self-regulated way.

\subsection{Other Metacognitive Components in Written Composition: Self- control, Motivation and Creativity.}

As we have already put forward in the previous section, (see Figure 1), the metacognition of written composition is not a purely cognitive process of building texts, but one in which other variables of a cultural and personal nature are influential. These are:

A. Self-control of emotions that allows emotional selection and concentration;

B. Extrinsic motivation triggered by an appropriated emotional environment; 
C. Intrinsic motivation, displayed by a clear cultural identity based on a positive self-concept;

D. Creative capacity, understood as autonomy and personal expression of values, reflected in the choice of strategies used to build a text and in the content, style, structure and purpose of that text.

A) Self-control of emotions (see Figure 1). This metacognitive ability allows the writer to choose natural emotions, in order to direct written communication. To do so, the writer applies the cultural ability (learnt in the group) of self-controlling his//her own emotions, to achieve the necessary state of concentration that the task of written composition requires.

The discoveries of neurology are outlining the central role of emotions in the dynamics of the human brain: "These discoveries are in keeping with the empirical evidence that underpins the intimate link between emotional reactions and the rest of mental operations in reading and written composition” (Dipardo \& Schnack, 2004, 18). We may state, then, that the emotional state of a subject may hinder or favour both the learning and the activation of the processes of written composition (Flower, 1994). This statement is directly linked with the need of performing a learning of the self-control of emotions when writing a text. However, self-control does not mean suppressing or repressing emotions but instead achieving the concentration needed in order to selfregulate writing processes, allowing the flow of the proper feelings for the contents, style and purpose of the text that is being written. A text without an emotional charge is a non-appealing text, one that does not convey the message to the reader; one which, in short, makes communication difficult, the latter being the goal of every text and every writer.

B) Extrinsic motivation for written composition (see Figure 1). This metacognitive capacity favours the proper, balanced and optimum building of a component from the context, which determines the subject's motivation in the learning of writing: the emotional climate.

"Affectiveness is a dimension of human beings with which we interiorise the task from a specific social and cultural interaction” (Vygostky, 1986, 182). The social and cultural interaction, in the case of written composition, is framed by the semiotic character of the language used, that is, by the network of verbal meanings in which the tasks of written composition are woven. Thus, the affections and disaffections that come 
forth from this network of meanings favour or hinder the significant learning of all writing tasks, to which the subjects are faced in those situations of interaction. This illustrates the importance of promoting emotionally positive contexts for the learning of written composition.

A positive emotional context for the development of written composition has nothing to do with mawkishness and flattery, but is closely related with the degree of appreciation received by the subject when he/she faces writing tasks. This extrinsic appreciation (received by the writer) pushes the subject's will towards the performance of the effort required by these complex tasks. An emotional climate that values novel writers and, therefore, extrinsically motivates them, is a climate dominated by the:

- variety and quality of the support (human and material) the subject gets in his/her writing tasks (mediation);

- objective assessment (made by him/herself and by the others) of the progress and mistakes of the subject in the writing tasks he/she faces;

- personalised positive reinforcements that the subject gets, according to that objective assessment;

- Constructive correction (reasoned out and with viable alternatives) of the writer’s mistakes.

C) Intrinsic motivation of written composition (see Figure 1). The appreciation of writers is related to other fields of interest in the affective-emotional studies. In that field of study, the building of the cultural identity of every subject in the process of development of written composition is explored, providing the subjects with opportunities to communicate of aspects related with their culture by means of the writing (McCarthey, 2001). The starting point is that the building of cultural identity is modelled by the development of the subject as a writer and, at the same time, the building of a defined cultural identity favours the learning and improvement of written language. This relationship between writing development and cultural identity is what causes the intrinsic motivation of the subject to devote him/her to written composition tasks. These relationships are explained in Figure 2. 


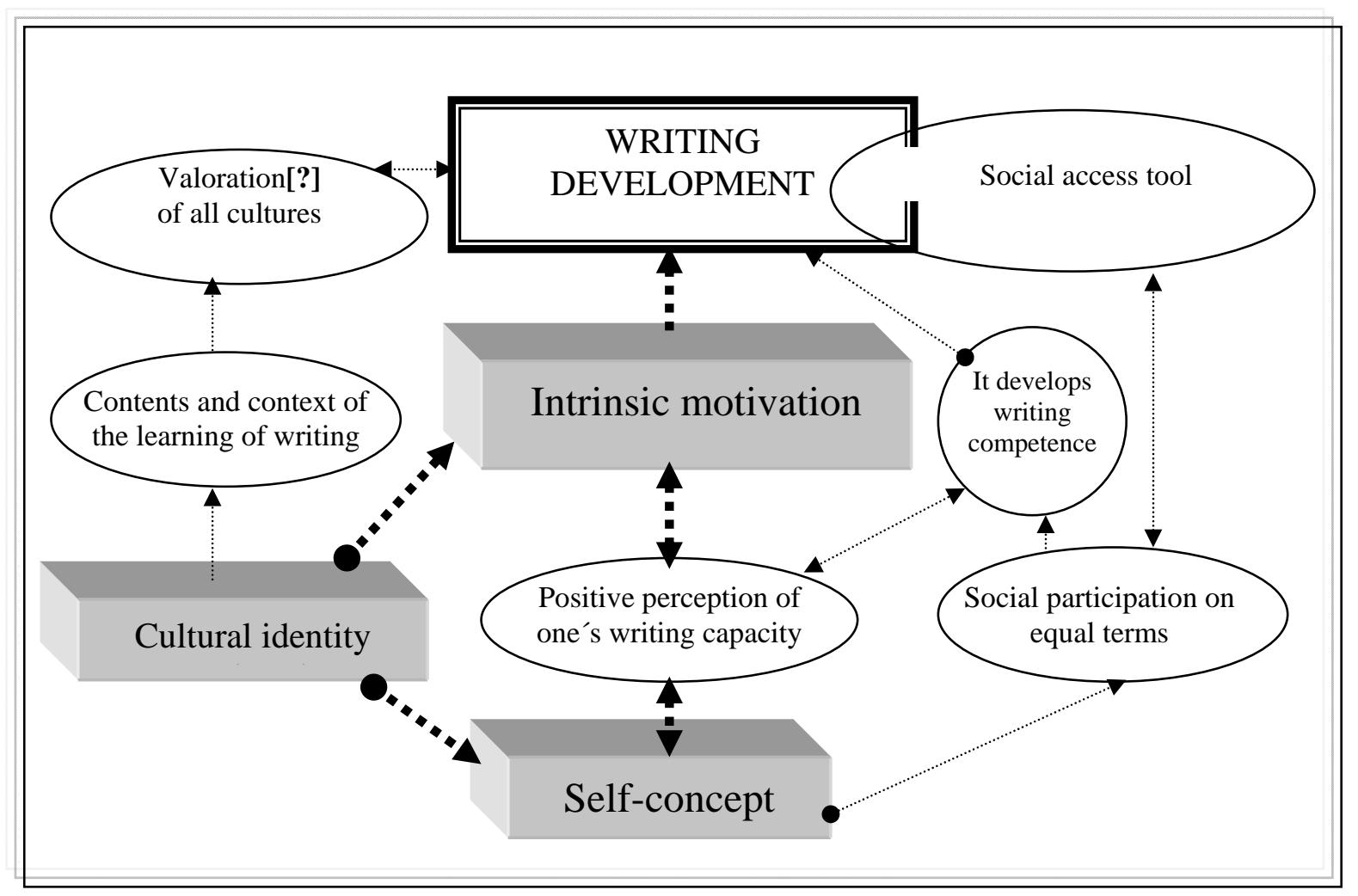

Figure 2. The relationship between intrinsic motivation, self-concept, cultural identity and the development of written composition.

The main influence exerted by the group over individuality is the building of the identity of that group's members, linked with the knowledge, affection and behaviour of that group. This identity structures itself from: a) the evaluation that the subject has of the group (according to the level of mastering of the cultural competences passed on by the group); b) the opposition towards the identity attached to the external group, so that this process happens even between groups of the same nature. Thus, "in those cases in which there is a greater contrast between the groups, the comparison will be stronger and identity will be more acutely stressed" (Tajfel, 1981, 225). We can prove, then, that cultural identity relates to the subject's self-concept (self-perception of one's own moral and social competence, according to his/her own assessment and that of his/her group).

These processes (cultural identity and self-concept) are natural and necessary for personal development, so that a clearly defined identity (structured around a series of fundamental shared values) promotes the development of a positive self-concept and allows the discovery of not only what differentiates the group and the subject from the rest, but also the things they have in common. It therefore allows personal and group enrichment: a) by knowing contrasts and complements; b) by enjoying what unites us; c) by overcoming conflicts in the definition of new goals. On the contrary, a confused 
identity (woven on superficial features) favours an ambivalent self-concept (the subject receives opposite assessment in different contexts, without being able to integrate these assessments in a deep network of meanings) which seriously hinders its adscription to wider cultural identities.

Since written composition is the main tool of access to western societies, the consideration of the different cultural competences of the different citizens (as content and context of the development of written composition) will allow the social valuation of all cultures and, therefore, of all individuals and collectives ascribed to them. At the same time, this individual and collective valuation of all cultures will favour the creation of defined cultural identities, a fact that is likely directly to affect the intrinsic motivation for the learning of writing. This intrinsic motivation will have repercussions such as that of a better writing competence and that of the self-perception of writing efficiency determined by a positive self-concept.

Taking into account everything already stated, cultural identity (based on a positive self-concept) is the factor that influences the subject's intrinsic motivation for written composition. Therefore, the building of cultural identity in the processes of written composition cannot be ignored, if we expect these to make every citizen's social participation possible (these citizens being part of multicultural societies of the $21^{\text {st }}$ century) on equal terms.

In short, metacognitive knowledge in written composition, apart from procedural, declarative and conditional knowledge, also includes: a) knowing which emotional and affective conditions are most appropriate in order to compose a text; b) self-controlling one's own emotional state; c) providing positive affective interactions; d) applying strategies so that the development of written composition may contribute to strengthen and develop one’s own cultural identity.

D) Finally, it must be highlighted that in the metacognition process a very important dimension for the holistic development of the writer is included (possibly the ultimate purpose of the learning of writing and of any human learning): creativity. Conditional knowledge involves selecting and applying different types of strategies in order to achieve the pursued goal with the written text. The selected and rebuilt strategies by the writer will make it possible to develop the processes of written composition and perform writing operations in a wholly autonomous way, achieving, in 
this way, his/her particular texts, that may give new experiences (ways of thinking and feeling) to others.

In the same way, personal self-control and a positive affective climate that build defined cultural identities (in the terms previously stated) are basic conditions for widening the subject's world of experience, being this one the essential matter with which written language is rebuilt and re-elaborated in a new and original way, for the expression of old or new contents. In short, the development of written composition has an ultimate irreplaceable goal: to develop the creative ability of human beings in order to improve his/her group and society.

\section{METACOGNITION AND SOCIAL DEVELOPMENT OF WRITTEN COMPOSITION}

In the previous section, we have defined contextual variables that may favour or hinder the development of the cognitive processes of written composition. These variables are the emotional-affective 'climate' and cultural diversity. The importance of social processes on written composition was also pointed out in order to elaborate a metatextual knowledge (theory of the text), when highlighting the semiotic nature of written language, whose meanings are the result of social interaction.

To describe written composition from a socio-cultural perspective is to understand that, in the socio-cultural and physical spaces and times in which metacognitive processes of written composition operate, we can identify other processes with the label of "socio-cultural" which are conditioning writing tasks and textual products, with more strength (sometimes) than pure cognitive processes (Sperling \& Warshauer, 2001)

From this perspective, it is argued that cognitive processes are performed generally in an unconscious way. As a result, textual products are usually copied, in their purpose, form, contents and structure, what is culturally experienced, or economically and politically persuaded, by the social context in which the subject lives and from which the text emerges. Even where metacognitive learning allows awareness, verbalizing, self-regulating and self-controlling (even recreating) of the cognitive processes, operations and strategies, this metacognitive reflection and update is not in charge of awareness, verbalizing, self-regulation and self-control of socio-cultural processes which influence the final product and even determine the cognitive operations 
and strategies applied. This is so because: 1) the matter which uses the cognitive processes of written composition is written language, which, in its contents, structure, form and purpose is the product of socio-cultural processes; 2) the subject's identity, which is expressed with that written verbal language, is also a product of socio-cultural processes.

\subsection{Socio-cultural Processes in Written Composition}

It is easy, therefore, to fall into the reductionism of understanding the process of written composition from only the metacognitive processes that the individual performs, or from the influence of the socio-cultural context. To consider the socio-cultural processes that work in written composition does not mean to lose the consideration of written composition as an individual cognitive process and a personal product but to direct the attention towards the fact that writer and text are immersed in a series of related contextual processes.

Socio-cultural reflection and research on written composition reveals that sociocultural processes, at least, are related to:

- The way in which the writer develops his/her metacognitive processes. The individual's experience and socio-cultural demands influence the purpose by which he/she writes, the written language and the codes used, the topic chosen, the contents selected, the structures applied, the style displayed, the material support used;

- Giving priority to some processes and cognitive operations over others. This means that, according to the socio-cultural processes experienced by the subject, the development of written composition may focus more on planning or on transcription or giving more attention to the selection of ideas than to the structure of the text;

- the conceptualisation of one's own written composition, either as a motorlinguistic act, as a unique linear process, as a universal recursive process, or as a diverse process (common and differentiated);

- Assessments and counter-assessments - expressed in the development of written composition. Human production is always the expression of values and antivalues, that is to say, ways of living (we live the way in which we value or we live what we value, even though we may assess and counter-assess. The 
development of written composition (processes, operations, strategies and contents, as well as the language used) expresses assessments and counterassessments (different ways of thinking, acting and feeling) product of the sociocultural processes lived by the subject.

In conclusion, the socio-cultural perspective suggests that a series of processes of a socio-cultural character affect the development of written composition. Schultz \& Fecho $(2000,55)$ suggest what these processes could be:

1. the social process in which the development of written composition is framed;

2. the local socio-affective process around the writer;

3. the didactic process of learning written composition;

4. the social relations between the subjects in their learning of writing;

5. the building of cultural identity within each writer;

6. The reconceptualisation of written composition as a complex and diverse interaction.

This suggestion considers processes, rather than variables, because the sociocultural context is diverse, dynamic and in progressive construction. It interacts with the individual cognitive processes. It is not appropriate to define the socio-cultural context as a series of static variables that have an invariable influence on the cognitive processes of written composition.

In the socio-cultural perspective, the development of written composition is not possible without a conceptualisation that describes its relationship with socio-cultural processes. This conceptualisation of written composition is not a closed definition but a process of self-reflection (individual reflection) and reflexivity (collective reflection) on the development of written composition, with the purpose of understanding the ways in which:

a) Written composition is a cultural tool which reflects historical, political and economic processes and how these may be used to direct processes of social improvement; 
b) Written composition develops in diverse local contexts, in which it assumes different forms and purposes, and from which it may be possible to investigate its functions for individuals and the wider community;

c) The pedagogic model used for the teaching of written composition affects its development;

d) Collaboration between subjects influences the cognitive and social development of written composition;

e) The development of written composition contributes to the process of building the subjects' cultural identity.

f) The development of written composition is linked to the processes of cognitive and social reflection.

These considerations suggest that, essentially, the development of written composition is not consistent for all subjects. Although a series of basic common metacognitive processes have been identified (planning, transcription, revision, memory, self-control, creativity, self-regulation, reflection...), these do not activate in the development of written composition as a whole and do not occur in the same way for all writers. Every process is operated differently, according to the socio-cultural processes that were suggested above: historical, political, economic, and local contexts; pedagogic model, social relationship, cultural identity, reflexivity.

\section{2.- Connection between Metacognitive and Socio-cultural Processes}

While metacognitive processes encourage the writing action, in other words, these processes are necessary to exercise, in a guided way, and make the writer aware of the writing cognitive processes. Social processes are contextual realities that are reflected in the subject's written composition, normally in an unconscious or subliminal way. Therefore, they require collective reflexive critical efforts in order to be able to regulate these effects in a positive way.

These reflections imply the understanding of written composition as a complex, dynamic and individualised interaction of processes, which does not advance according to a normative and fixed model. Instead, it demands the activation of reflective processes (self-reflection) and reflexivity (collective reflection) for written composition 
to be appreciated as a means of personal and social development, rather than as a matter of imitation, mechanical reproduction or ideological alignment.

Appreciating written composition in this way is likely to facilitate an understanding that the development of written composition is the product of a diversity of processes, both metacognitive and socio-cultural, and that between these there are multiple 'connecting cores' and also between these cores and the text.

The first connecting core is identified when updating metatextual knowledge or "theory of the text" (conditional process of written composition). As it has already been explained, metatextual knowledge is semiotic in nature and is a knowledge that refers to the system of verbal symbols (written language) that the subject uses for the expression of a textual content. This system of symbols is acquired in the discursive processes of social interaction, which are formed in the text through the metacognitive processes of written composition.

The second connecting core between metacognitive and social processes is constituted by the affective climate. The affective climate (as has already been mentioned) favours the extrinsic motivation for the tasks of the learning of writing (metacognitive component of written composition). The affective climate, in turn, is also conditioned by two social processes: the didactic process or pedagogic model followed in the teaching of written composition; and the interpersonal relationships that are activated in the development of written composition.

The third connecting core between metacognitive processes is identified in the process of building the subject's cultural identity, which interacts with the metacognitive processes of written composition and these with the text. As has already been argued in this paper, the text (language, contents, structure, form and purpose) reflects each individual's cultural identity, which comes from the assessments and counter assessments present in the socio-cultural processes experienced by the subject in his/her development of written composition. It was also pointed out that the process of building of cultural identity (as a metacognitive component of written composition) is influenced by, and exerts its influence on, the cognitive processes of written composition through: a) the intrinsic motivation for the writing tasks; b) the selection of strategies, selected for and applied to the composition of the text. Cultural identity is thus linked to the cognitive processes of written composition, to wider socio-cultural processes and to the text itself. 
In short, the codes of written language, the affective climate and an individual's cultural identity form a great 'loom' that allows for the entwining of metacognitive processes and socio-cultural processes in order to weave the complex tapestry of written composition. The loom analogy carries with it the related analogy of disentangling the 'hanks' of the socio-cultural and metacognitive processes. In order to do this, it is suggested that, in the development of written composition, the subject must become aware of the socio-cultural processes in the operative and verbal levels and therefore be able to choose those socio-cultural strategies that may allow the composition of the text in a self-regulated way, according to the goals and social functions proposed with that writing. But, is not this, perhaps, procedural, declarative and conditional knowledge about the socio-cultural processes, that is to say, “metasocioculturisation”? But, instead of talking about "metacognition” and "metasocioculturisation” of written composition, it would be more appropriate to propose a new metasociocognitive process in which to include as processes of written composition not only the cognitive ones but also the socio-cultural ones, with the mentioned process assuming new operations (see picture 3):

- The self-regulation of socio-cultural processes.

- The interaction between socio-cultural processes and the text

- The interaction between metacognitive and socio-cultural processes and between both and the text. 


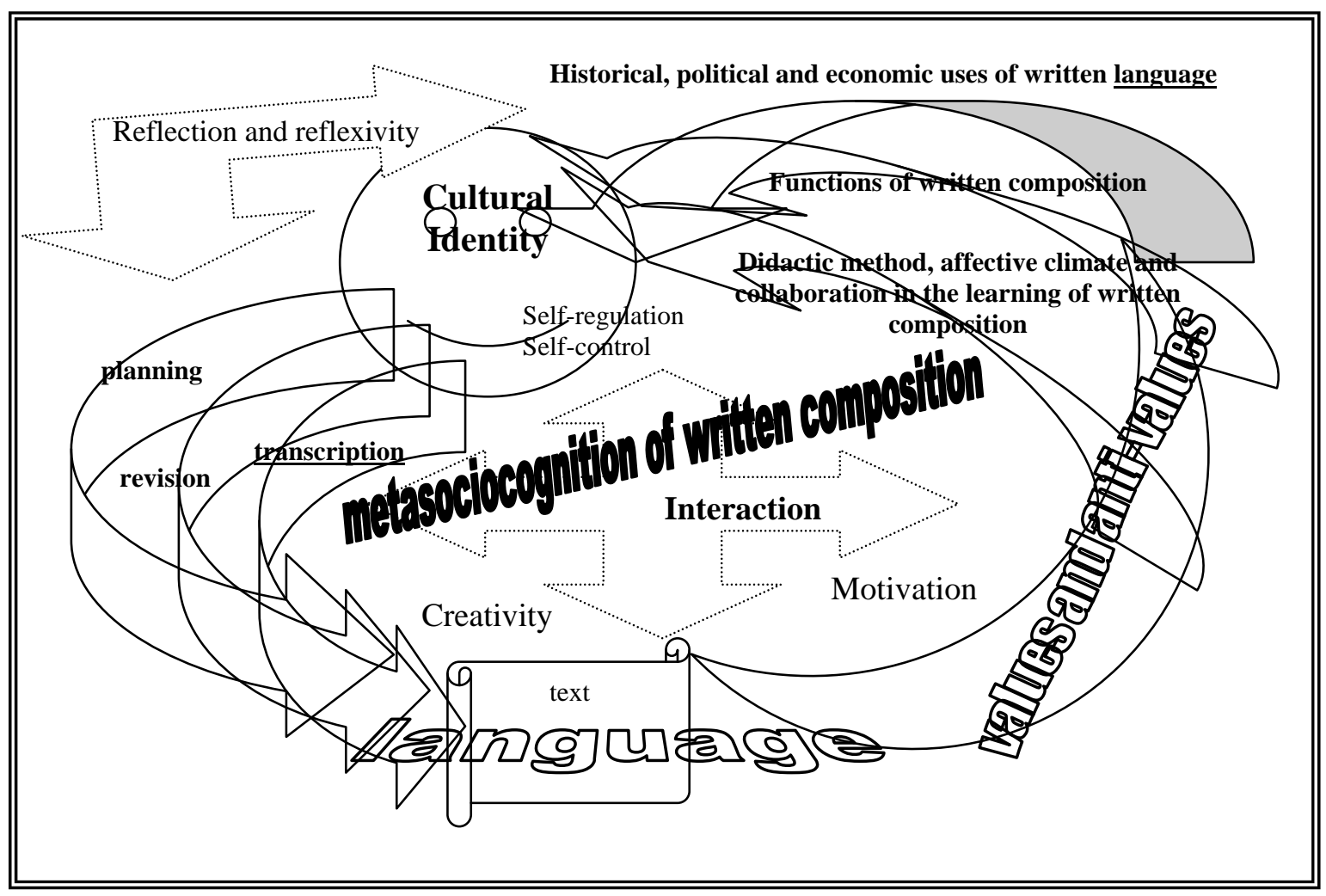

Figure 3. Interactive model of written composition

This model of written composition is in its formative phase. Research is needed to determine the strategies that may influence how socio-cultural processes interact with the cognitive strategies of written composition.

\section{INTERCULTURAL DEVELOPMENT OF WRITTEN COMPOSITION.}

Intercultural development in written composition is a demand of the current multicultural societies. To talk about multiculturalism is to place oneself in a conceptual space which describes socio-politic, economic and individual situations, characterised by the diversity of ethnic groups or anthropologically distant cultures. A multicultural context is that one in which social interactions are presided by every culture's awareness, by means of an attitudinal positioning of respect towards differences (Arroyo, 2000).

Graham \& Harris (2005a, 2005b) have, since the 1990s, been investigating the teaching of the cognitive processes of written composition to pupils belonging to the 
Afro-American people with learning difficulties. We can infer from their studies that, in these contexts of cultural diversity and socially, politically and economically impoverishment, the development of written composition is a multidimensional one. Multiple writing abilities are developed, which involve the subjects' knowledge and motivation. These authors propose strategies for the development of written products: a) to change the knowledge of the subjects on how they write; b) to increase their knowledge of what is writing; and c) all of this dynamised by a series of motivating tasks. These strategies are designed in order to provide the subjects with a basic tool of cultural integration, as written composition is, and thus help them to participate in the social institutions of which they are part.

However, from an intercultural perspective (or planned action, which expects intercultural exchange on equal terms in order to achieve a shared social progress) (Arroyo, 1998, 2001), written language, apart from being considered as a basic communicative skill of social participation, is also considered as cultural instrument for the production of reasoning and reflexivity processes which favour personal and social development. In this sense, the development of written composition is linked to a series of personal and social purposes that promote diversity (unity and difference). These purposes are as follows:

- Mastering a common means of human interaction - a written language. When the social context that surrounds written composition's development is presided by a culture with an official language, an intercultural option can not deny how this official language reflects a common exigency for participation in society . For purely pragmatic purposes, the intercultural perspective of written language will give priority to the socially predominant written language, while continuing to value (the written composition in other languages, the exponents of cultural diversity. However, it is important not to overlook that there is also a demand for the development of multilingual written composition in different languages, to enrich both the personal and social development of individuals.

- Becoming aware of the stereotypes and prejudices expressed in the development of written composition towards people with different ethnic origin or social and/or cultural condition that may reflect discrimination or political and economic exclusion. This will allow, on the one hand, the dismissal of the discrimination practices and, on the other hand, the positive assessment in the 
process of development of written composition of all persons, whatever their social, cultural and personal circumstances.

- Accepting that the assessments and counter-assessments and cultural features (dogmatism and fundamentalism) expressed by different texts are representative of the cultural diversity of the social context. This will allow the exercise of freedom, from the compromise for: a) the respect towards any expression of value; b) the critics of any expression of counter-assess c) the exposure of any attempt of manipulation. This option, at the same time, makes the creation of defined and rich identities possible, that is: a) solid and dynamic; b) confident and critic; c) structured and flexible; d) stable and adaptable; f) deep and open. In short, these are re-creators of diverse socio-cultural values and creators of new forms of expression (Bourne, 2001).

This intercultural development uses written composition as a tool to make possible equal opportunities in politics and economy for all individuals from their different contributions. Therefore, to promote cultural diversity with written composition is to promote equal rights and the freedom to choose one's own way of living. It also represents politically and economically participating in society, respecting all personal and collective differences. These developments will be achieved by combining cognitive-affective strategies with socio-intercultural strategies. This will extend recent work in the teaching of written composition (Arroyo, 2006) where, apart from cognitive strategies, strategies for "the reflection on the social use of written composition" and for "the collective and self-regulated representative texts of cultural diversity" have been applied.

\section{BIBLIOGRAPHY}

Arroyo, R. (1998). Intervención didáctica en procesos lectores desde la perspectiva intercultural. Enseñanza. Anuario Interuniversitario de Didáctica 16, 367-295.

Arroyo, R. (2000). Diseño y desarrollo del currículum intercultural. Los valores islámicosoccidentales. Granada. Servicio de publicaciones de la Universidad.

Arroyo, R. (2001). Dependencia e independencia de valores por edad y cultura: presupuestos del Currículum Intercultural. Revista de Investigación Educativa 19 (1), 153-182.

Arroyo, R. (2005a). La enseñanza de la composición escrita en un contexto multicultural: Estudio de un Caso. En Salvador, F. (Ed..) La expresión escrita de alumnos con necesidades educativas especiales. Procesos cognitivos.. Archidona: Aljibe, 139-177

Arroyo, R. (2005b). Problemas relacionados con el contexto multicultural. Evaluación e intervención educativa. En Salvador, F.(Coord.) Bases Psicopedagógicas de la Educación Especial (pp:299-320). Archidona: Aljibe. 
Arroyo R. (2005c). Estrategias didácticas para la enseñanza de metacognición de la composición escrita en contextos multiculturales. Educación Desarrollo y Diversidad, 8 (3), 3150

Arroyo, R. (2006). La interculturalidad en los procesos de la composición escrita. Investigación en la escuela, 59, 91-102

Beard, R. (2000) Developing Writing 3-13. London: Hodder \& Stoughton.

Beard, R. (2005). Teaching writing: Using research to inform practice. In G. Rijlaarsdam, H. Van den Bergh and M. Couzijn (eds.) Research in Effective Learning and Teaching of Writing. Amsterdam: Kluwer.

Brounw, A. L. (1985). Metacognition: the developemnt of selective attetion strategies for learning from tesxts. En H. Singer, y R Ruddell. (eds). Theoretical Models and Processes of reading. Delaware: NJ: I.R.A, 85-107.

Bourne, J. (2001). Discourses and identities in a multi-lingual primary classroom. 27 (1), 103114

Bruning, R. y Horn, C. (2000). Developing motivation to write. Educational Psychologist, 35 (1)25-37.

Dipardo, A. y Schnack, P. (2004). Expanding the web of meaning: thought and emotion in an intergenerational reading and writing program. Reading Research Quarterly, 1(39), 14-37.

Flavell, J (1985). El desarrollo cognitivo. Madrid: Visor.

Flower, L (1994). The construction of negotiated meaning: a social cognitive Theory of writing Carbondale, IL:Southern Illinois University Press.

Graham, S. y Harris, K. (1999). Making the writting Process work: strategies for composition and self-regualtion. Massachusetts: Brookline Books.

Graham, S. y Harris, K (2005a). Writing Better: Strategies for Teaching Students with Learning Difficulties. Baltimore:Brookes Publising.

Graham, S. y Harris, K. (2005b). Improving the writing Performance of young Struggling Writers: Theoretical and Programmatic Research From the Center on Accelerating Student Learning. The Journal of Special Education 39 (1), 19-33.

Hayes, J.R. (1996). A new framework for understanding cognition and affect in writing process. En. Levy, C.M y Ransdell, S.R. (Eds.). The Sciences of Writing. Hillsdale, NJ: Lawrence Erlbaum Associates, 3-30.

McCarthey, S. (2001). Identity construction in elementary readers and writers. Reading Research Quarterly 36 (2), 122-151

Peronard, M.; Velásquez, M.; Crespo, N y Viramonte, M. (2002). Conocimiento metacognitivo del lenguaje escrito: instrumento de medida y fundamentación teórica. Infancia y Aprendizaje, 25 (2), 131-145.

Salvador, F. (2005). Procesos cognitivos en la expresión escrita: Modelos teóricos e investigación empírica. En Salvador, F. (Edt.). La expresión escrita de alumnos con necesidades educativas especiales. Procesos cognitivos. Archidona: Aljibe 15-44.

Schultz; K. y Fecho, B. (2000). Society's child: Social Context and Writing Developmenet.

Educational Psychologist, 35 (1), 51-62.

Sperling, M. y Warshawer F.S. (2001). Research on Writing. En V. Richarson (Ed). Handbook of research on teaching (pp.370-389). Fourth Edition. Washington: American Educational Research Association.

Tajfel, H. (1981). Human Groups and Social Categories: Studies in Social Categories. Cambridge. Cambridge University Press.

Vigostky, L.S (1986). Thought and language. Cambridge, MA:MIT Press 